\title{
Prevalence of congenital malaria in high-risk Ghanaian newborns: a cross-sectional study
}

\author{
Christabel C Enweronu-Laryea ${ }^{1 *}$, George O Adjei ${ }^{2}$, Benjamin Mensah ${ }^{3}$, Nancy Duah ${ }^{4}$ and Neils B Quashie ${ }^{2}$
}

\begin{abstract}
Background: Congenital malaria is defined as malaria parasitaemia in the first week of life. The reported prevalence of congenital malaria in sub-Saharan Africa is variable $(0-46 \%)$. Even though the clinical significance of congenital malaria parasitaemia is uncertain, anti-malarial drugs are empirically prescribed for sick newborns by frontline health care workers. Data on prevalence of congenital malaria in high-risk newborns will inform appropriate drug use and timely referral of sick newborns.

Methods: Blood samples of untreated newborns less than 1 week of age at the time of referral to Korle Bu Teaching hospital in Accra, Ghana during the peak malaria seasons (April to July) of 2008 and 2010 were examined for malaria parasites by, i) Giemsa-stained thick and thin blood smears for parasite count and species identification, ii) histidine-rich protein- and lactic dehydrogenase-based rapid diagnosis tests, or iii) polymerase chain reaction amplification of the merozoite surface protein 2 gene, for identification of sub-microscopic parasitaemia. Other investigations were also done as clinically indicated.
\end{abstract}

Results: In 2008, nine cases of Plasmodium falciparum parasitaemia were diagnosed by microscopy in 405 (2.2\%) newborns. All the nine newborns had low parasite densities ( $\leq 50$ per microlitre). In 2010, there was no case of parasitaemia by either microscopy or rapid diagnosis tests in 522 newborns; however, 56/467 (12\%) cases of P. falciparum were detected by polymerase chain reaction.

Conclusion: Congenital malaria is an uncommon cause of clinical illness in high-risk untreated newborns referred to a tertiary hospital in the first week of life. Empirical anti-malarial drug treatment for sick newborns without laboratory confirmation of parasitaemia is imprudent. Early referral of sick newborns to hospitals with resources and skills for appropriate care is recommended.

Keywords: Congenital, Malaria, Newborn, Ghana

\section{Background}

Malaria in pregnancy is a major underlying cause of neonatal morbidity in endemic regions [1-3]. The burden of malaria in pregnancy is highest in sub-Saharan Africa where 1:4 pregnant women have evidence of placental infection at the time of delivery [4-6]. Pregnancy associated malaria has been implicated as a cause of stillbirths, premature births, intrauterine growth restriction and consequently low birth weight (LBW) in affected newborns. However, its effect as a cause of clinical disease in the newborn especially in the first week of life, when most newborn illnesses and deaths occur, is uncertain.

\footnotetext{
* Correspondence: chikalaryea@gmail.com

'Department of Child Health, University of Ghana Medical School, P O Box 4236, Accra, Ghana

Full list of author information is available at the end of the article
}

Congenital malaria, defined as malaria parasitaemia in the first week of life can be acquired transplacentally or during the time of birth. The prevalence in sub-Saharan Africa has been reported to vary from $0-46 \%$ [7]; however, more recent multicentre longitudinal studies have reported lower rates of $4-6 \%[8,9]$. Clinical malaria is rare in newborns from endemic areas with high incidence of malaria in pregnancy. This rare occurrence has been attributed to the transplacental transfer of maternally derived antibodies to malaria, and the inhibitory effect of foetal haemoglobin on malaria parasite development [10-12].

The prevalence of congenital malaria in a community based prospective study in infants in southern Ghana in 1998 was $13.6 \%$ by polymerase chain reaction (PCR) and $2.5 \%$ by microscopy [13]. In that study the risk of

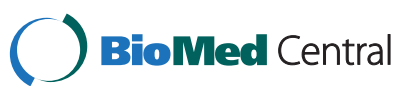


infection was three times higher during the rainy season (April - July) as compared to the dry season. Recently, two cases of symptomatic congenital malaria were reported in Ghanaian newborns $[14,15]$.

Clinical malaria in the newborn usually manifests after the first week of life (but has been reported on day 1) with symptoms such as fever, poor feeding, lethargy, anaemia, hepatosplenomegaly, jaundice, irritability, and drowsiness. These clinical features are similar to the manifestations of neonatal sepsis and other neonatal conditions that more commonly cause morbidity and mortality in the newborn period $[8,16,17]$. Many malaria endemic sub-Saharan African countries lack quality laboratory equipment and skilled frontline health care workers in primary health care facilities. As such, diagnosing neonatal problems is a major challenge and empirical treatment for malaria is often prescribed when newborns first present with the above symptoms. Sick newborns are referred to hospital few days later when malaria treatment does not resolve symptoms. This practice results in delayed referral of sick newborns for appropriate care and contributes to the high neonatal mortality and long-term morbidity in survivors in the subregion.

Malaria is endemic in Ghana and World Health Organization (WHO) guidelines for empirical treatment of malaria in suspected cases is widely adhered to [18]. This practice is extended to sick newborns by primary care health workers contrary to existing guidelines on the Integrated Management of Childhood Illnesses. Though many underlying reasons may account for this practice in sick newborns, the lack of sufficient local data on congenital malaria may be a contributory factor. This study presents the prevalence of malaria parasitaemia in non-treated high-risk newborns referred to a teaching hospital in the first week of life.

\section{Methods}

This cross-sectional study was done at the newborn unit and malaria research laboratory of the Department of Child Health, Korle Bu Teaching Hospital, in Accra during the peak malaria seasons (April - July) of 2008 and 2010. The 55-bed newborn unit serves as a tertiary referral centre for sick and low birth weight or preterm newborns from southern regions of Ghana. About 2000 newborns are admitted annually. Ethical approval was given by the Ethical and Protocol Review Committee of the University of Ghana Medical School.

All newborns hospitalized at the newborn unit in the first week of life during the study period were eligible for inclusion. Newborns with clinical indications that required blood sampling e.g. signs of illness or risk factors for infection were enrolled. Stable newborns e.g. infants of diabetic mothers or well preterm infants of hypertensive mothers who were referred for observation and did not require laboratory investigations, were excluded. All clinical procedures and laboratory investigations for hospitalized newborns were done according to standard and departmental guidelines.

A structured questionnaire was used to collect clinical data on newborn and maternal health during pregnancy, including use of insecticide treated nets and intermittent preventive treatment. Other clinical data was extracted from the ward register and hospital files. Sample size calculation was based on an estimated prevalence of a $20 \%$ risk of congenital malaria in high-risk newborns in the first week of life $[2,11]$.

\section{Laboratory investigations}

Newborn venous blood $(1 \mathrm{ml})$ was collected into EDTA tubes for haematological investigations. Total white blood cell count (WBC) with differential, platelet count and red cell distribution width was measured by an automated haematology analyzer (Sysmex KX-21) according to manufacturer's instructions. Thick and thin blood smears prepared from the EDTA sample were stained with Giemsa. Thin smears were used for malaria parasite species identification, and the number of asexual parasites per 200 white blood cells (WBC) on the thick smear was multiplied by the measured WBC count to obtain the parasite count per microlitre. An experienced technologist conducted periodic controls of blood slides for quality control. This traditional method of microscopy was used in 2008 and 2010. In 2010, a rapid diagnosis test (RDT) for identification of malaria parasite histidine rich protein 2 and lactate dehydrogenase (the First Response ${ }^{\circledR}$ malaria antigen pLDH/HRP2 Combo Test), and a nested PCR methods were used to identify sub-microscopic parasitaemia.

\section{RDT}

The First Response ${ }^{\circledR}$ malaria antigen pLDH/HRP2 Combo Test (Premier Medical Corporation Ltd, India) is designed for the differential diagnosis between Plasmodium falciparum and other plasmodial species. It contains a membrane strip pre-coated with two monoclonal antibodies as two separate lines across a test strip. One monoclonal antibody is pan-specific to lactate dehydrogenase of the Plasmodium species and the other monoclonal antibody is specific to histidine-rich protein 2 of P. falciparum [19].

\section{PCR}

This was done at the Noguchi Memorial Institute for Medical Research, University of Ghana. Parasite DNA was extracted from whole blood samples spotted on filter paper, using the TE method [20]. A nested PCR method for amplification of the merozoite protein 2 (MSP) gene was used for the detection of $P$. falciparum. The primary amplification reaction involved the use of 
the primer pair, S2 (5'-5' GAG GGA TGT TGC TGC TCC ACA G 3') for a $450-800$ base pair product. The PCR product obtained was used as the template for the secondary PCR using the following primer pairs: S1 (5'GAG TAT AAG GAG AAG TAT G-3') and S4 (5'-CTA GAA CCA TGC ATA TGT CC-3') for a 400-700 base pair product. The PCR reactions were carried out in a final volume of $25 \mu \mathrm{l}$, which contained $1 \mathrm{xPCR}$ buffer $(50 \mathrm{mM} \mathrm{KCl}, 20 \mathrm{mM}$ Tris- $\mathrm{HCl}, \mathrm{pH} 8.3,0.1 \mathrm{mg} / \mathrm{ml}$ of gelatin), $3.5 \mathrm{mM} \mathrm{MgCl} 2,200 \mu \mathrm{M}$ dNTP mix, $1 \mu \mathrm{M}$ of each primer, $1 \mathrm{U}$ Taq polymerase and $5 \mu \mathrm{l}$ of DNA template for primary amplification. The secondary reaction contained 1xPCR buffer $(50 \mathrm{mM} \mathrm{KCl}, 20 \mathrm{mM}$ Tris- $\mathrm{HCl}$, $\mathrm{pH} 8.3,0.1 \mathrm{mg} / \mathrm{ml}$ of gelatin), $2.5 \mathrm{mM} \mathrm{MgCl}, 200 \mu \mathrm{M}$ dNTP mix, $1 \mu \mathrm{M}$ of each primer, $1 \mathrm{U}$ Taq polymerase and $1 \mu$ of DNA amplicon. PCR was carried out using a DNA Engine Tetrad PTC-225 thermal cycler (MJ Research, USA) with cycling parameters of an initial melt at $94^{\circ} \mathrm{C}$ for 3 mins followed by 30 cycles of $94^{\circ} \mathrm{C}$ for 25secs, $42^{\circ} \mathrm{C}$ for $1 \mathrm{~min}, 65^{\circ} \mathrm{C}$ for 2 minutes and a final cycle of $72^{\circ} \mathrm{C}$ for 3mins. The cycling parameters for the secondary reaction was $94^{\circ} \mathrm{C}$ for 3 mins followed by 30 cycles of $94^{\circ} \mathrm{C}$ for $25 \mathrm{secs}, 50^{\circ} \mathrm{C}$ for $1 \mathrm{~min}, 70^{\circ} \mathrm{C}$ for 2 mins and a final cycle of $72^{\circ} \mathrm{C}$ for 3 mins. PCR products were run on a $2 \%$ ethidium bromide stained agarose gel. The PCR assay detects one parasite per microlitre of blood and has about $97 \%$ sensitivity and $100 \%$ specificity to detect $P$. falciparum.

\section{Data analysis}

Laboratory data was entered into a designated register. All data were subsequently entered into a database (Access 2007 for Windows, Microsoft Corporation, USA). Data analysis was by descriptive and inferential statistics. Pearson's chi square test (or Fisher's exact test as appropriate) was used to compare proportions.

\section{Results}

In 2008, 405 newborns aged $0-7$ days were tested in the first week of life. In 2010, 522 newborns admitted to the unit in the first week of life were tested during the course of their hospitalization (aged $0-28$ days), of these $443(84.9 \%)$, were tested in the first week of life. The number and selected demographic and clinical characteristics of newborns admitted during both study periods are shown in Table 1 . There was no difference in the morbidity pattern of newborns during both periods.

Nine (2.2\%) of the 405 newborns tested in 2008 had $P$. falciparum parasitaemia by microscopy, all of which were of low parasite density ( $\leq 50$ per $\mu \mathrm{l})$. Four $(44 \%)$ of the nine newborns were LBW and also born prematurely. Of the nine affected newborns, two were asymptomatic preterm LBW newborns who needed special
Table 1 Characteristics of newborns tested for congenital malaria in 2008 and 2010

\begin{tabular}{|c|c|c|}
\hline & Newborns in 2008 & Newborns in 201 \\
\hline & $n=405(\%)$ & $\mathrm{n}=522(\%)$ \\
\hline \multicolumn{3}{|l|}{ Birth weight } \\
\hline$<2500$ grams $($ LBW) & $223(55)$ & $267(51)$ \\
\hline$\geq 2500$ grams & $182(45)$ & 255 (49) \\
\hline \multicolumn{3}{|l|}{ Reason for admission } \\
\hline Prematurity/LBW & $161(39.8)$ & $185(35.4)$ \\
\hline Suspected infection & $119(29.4)$ & $152(29.1)$ \\
\hline Perinatal asphyxia & 78 (19.3) & $110(21.1)$ \\
\hline Jaundice & $31(7.7)$ & $43(8.2)$ \\
\hline $\begin{array}{l}\text { Other (birth injury, congenital } \\
\text { anomalies, intrapartum } \\
\text { maternal death) }\end{array}$ & $15(3.7)$ & $32(6.1)$ \\
\hline \multicolumn{3}{|l|}{ Laboratory data } \\
\hline Mean haemoglobin (g/dl) & $\begin{array}{l}15.5 \text { (range } 4.1- \\
23.7)\end{array}$ & $\begin{array}{l}15.4 \text { (range } 5.7- \\
23 \text { ) }\end{array}$ \\
\hline $\begin{array}{l}\text { Mean white blood cell count } \\
\left(\times 10^{9}\right)\end{array}$ & $\begin{array}{l}10.4 \text { (range } 2.1- \\
37.4 \text { ) }\end{array}$ & $\begin{array}{l}12.8 \text { (range } 3 \text { - } \\
\text { 23) }\end{array}$ \\
\hline
\end{tabular}

There was no difference between subjects' characteristics in 2008 as compared to 2010 ( $p>0.05$ for all parameters).

care, three had suspected sepsis (they had no fever) because of risk factors for neonatal infection in their mothers' obstetric history, three had perinatal asphyxia and one newborn was admitted on the $7^{\text {th }}$ day of life with low grade fever and moderate jaundice. The mean haemoglobin and WBC in newborns with congenital malaria was $[15.5 \mathrm{~g} / \mathrm{dl}$ (range $13.2-17.8$ ) $]$ and $[10.5 \times$ $10^{9}$ (range $4.2-19.4$ )] respectively. There was no statistical difference in the haematological indices of congenital malaria cases as compared with non-affected newborns (see Table 1). Affected newborns were treated with amodiaquine $10 \mathrm{mg} / \mathrm{kg} /$ day according to departmental guidelines.

None of the 522 newborns recruited in 2010 had parasitaemia by microscopy or RDT. All 522 samples were tested by PCR, results were obtained in $467 / 522$ and 56 (12\%) newborns were positive for P. falciparum. The prevalence of LBW in the PCR parasitaemia-positive newborns was $55 \%$ as compared to $41.9 \%$ in those who were PCR parasitaemia-negative $[\mathrm{p}=0.1$; RR $1.3(95 \% \mathrm{CI}$ 0.9 - 1.74)]. The mean haemoglobin $(14.6 \mathrm{~g} / \mathrm{dl}$ vs. $15.3 \mathrm{~g} / \mathrm{dl})$ and WBC $\left(14.6 \times 10^{9}\right.$ vs. $\left.16.4 \times 10^{9}\right)$ in those with parasitaemia vs. those without parasitaemia respectively was not statistically different.

Data collected from mothers about their health and malaria preventive practices (use of insecticide treated nets and intermittent preventive treatment) during pregnancy were not analyzed because the information could not be verified. 


\section{Discussion}

This study shows that patent malaria parasitaemia was uncommon in untreated high-risk newborns referred to Korle $\mathrm{Bu}$ Teaching hospital in southern Ghana during the peak seasons for malaria in 2008, and 2010. The $2.2 \%$ congenital malaria prevalence by microscopy in the 2008 cohort was lower than rates from longitudinal studies from neighbouring countries, $5.1 \%$ in Nigeria and $4.7 \%$ in Ivory Coast $[8,9]$. The data also suggests that congenital malaria is mostly asymptomatic with no pathognomic clinical features and that affected newborns have low parasitaemia; these findings are similar to work reported by others [21,22].

Several hospital-based studies from the West African sub-region have reported high prevalence of malaria in newborns [23,24]. The reasons for the variable prevalence of congenital malaria in these countries of similar endemicity as Ghana are unclear. Possible explanations could be differences in malaria prevention coverage during pregnancy or laboratory operational factors. Traditional microscopy in routine service laboratories may over-diagnose malaria, and has been shown to have a poor positive predictive value when compared with microscopy from research laboratories [25,26].

The PCR method diagnoses congenital malaria more frequently because of its ability to detect parasite macromolecules and not necessarily live parasites [21]. The clinical importance and significance of malaria parasitaemia diagnosed by PCR alone is uncertain [27]. Even though it is suggestive of placental parasitaemia and the consequent effects of LBW and prematurity but its relevance as a significant cause of clinical illness in the first week of life is doubtful. However, recent evidence suggests that $P$. falciparum malaria parasites in the placenta as detected by PCR are more likely to result in congenital malaria in the infant during the first three months of life [28].

Most widely used RDTs are based on the detection of the histidine-rich protein 2 (HRP2) product of the P. falciparum hrp 2 gene. The sensitivity and specificity of this method has been shown to range from $90-95 \%$ and $85-92 \%$ respectively. However, relative to thick smear microscopy, recent studies have shown that false negative RDT results occur in persons with asymptomatic P. falciparum infections as in our patients. The false negatives are thought to result from spontaneous deletion of the histidine-rich repeat region of the hrp2 gene [29].

The data from this study and previous communitybased study on congenital malaria in Ghana [15] shows that congenital malaria is an uncommon cause of neonatal morbidity in Ghana. A large-scale hospital-based surveillance study in Kenya from 2002 - 2009 found a declining trend in the prevalence of congenital malaria; newborns $(0.5 \%)$ who had malaria parasitaemia presented before 2005 [30]. Other workers have also shown a declining trend in malaria disease in recent years [31,32]. These studies suggest that clinical congenital malaria is not a significant cause of the high neonatal morbidity and mortality in sub-Saharan Africa. It is therefore important that sub-Saharan African countries with endemic malaria should urgently review newborn care guidelines for primary health care workers so as to reduce delays in the referral and appropriate management of sick newborns.

This study has some limitations. Though one of the objectives was to identify the impact of maternal malarial preventive practices in pregnancy on the prevalence of congenital malaria, we could not collect accurate data on maternal practices. It was difficult to verify that those who said they had used insecticide treated nets during pregnancy actually did so. Also, the information mothers gave on intermittent anti-malarial prophylaxis was not always recorded in the available maternal health records.

\section{Conclusion}

The data from this study does not support empirical treatment for malaria in sick newborns in Ghana. Laboratory confirmation of malaria in newborns should be done and other causes of clinical illness excluded before antimalarial drugs are prescribed for newborns especially in the first week of life. The prevalence of malaria as detected by PCR in this study could be used to make a case for improving malaria preventive practices during pregnancy thus reducing placental malaria - a known cause of LBW and a pre-requisite for congenital malaria. Early referral of sick newborns to health facilities with adequate skills for early diagnosis and appropriate management is recommended. Concerted effort to reduce empirical prescription of anti-malarial drugs for newborns is needed. Data such as presented in this study could be used in continuing educational programs to improve knowledge and influence the practice of frontline health care providers.

\section{Abbreviations \\ LBW: Low birth weight; PCR: Polymerase chain reaction; RDT: Rapid diagnostic test; WBC: White blood cells; WHO: World Health Organization.}

\section{Competing interests}

The authors have no competing interest to declare. None of the authors received any remuneration for this work. The laboratory investigations of this study were partly supported by DANIDA Denmark (DFC grant number 09-080RH).

\section{Authors' contribution}

CEL conceived the study and worked with GOA and BM on the design and data acquisition. GOA, BM, ND and NBQ did the laboratory work. CEL drafted the manuscript and all 5 authors participated in the several revisions of the manuscript and gave approval for the final version for publication.

\section{Acknowledgement}

We are grateful to Juanita Adams for her diligent work in data entry.

\section{Author details}

${ }^{1}$ Department of Child Health, University of Ghana Medical School, P O Box 4236, Accra, Ghana. ${ }^{2}$ Centre for Tropical Clinical Pharmacology and 
Therapeutics, University of Ghana Medical School, Accra, Ghana. ${ }^{3}$ Department of Haematology, Korle Bu Teaching Hospital, Accra, Ghana. ${ }^{4}$ Department of Epidemiology, Noguchi Memorial Institute for Medical Research, University of Ghana, Accra, Ghana.

Received: 4 September 2012 Accepted: 27 December 2012 Published: 11 January 2013

\section{References}

1. Brabin BJ: An analysis of malaria in pregnancy in Africa. Bull World Health Organ 1983, 61:1005-1016.

2. Fischer PR: Congenital malaria: an African survey. Clin Pediatr 1997, 36:411-413.

3. Breman JG, Alilio MS, Mills A: Conquering the intolerable burden of malaria: what's new, what's needed: a summary. Am J Trop Med Hyg 2004, 7(Suppl 2):1-15.

4. Desai M, ter Kuile FO, Nosten F, McGready R, Asamoa K, Brabin B, Newman RD: Epidemiology and burden of malaria in pregnancy. Lancet Infect Dis 2007, 7:93-104.

5. Guyatt HL, Snow RW: Impact of malaria during pregnancy on low birth weight in sub-Saharan Africa. Clin Microbiol Rev 2004, 17:760-769.

6. Guyatt HL, Snow RW: Malaria in pregnancy as an indirect cause of infant mortality in sub-Saharan Africa. Trans R Soc Trop Med Hyg 2001, 95:569-76.

7. Uneke CJ: Congenital Plasmodium falciparum malaria in sub-Saharan Africa: a rarity or frequent occurrence. J Parasitol Res 2007, 101:835-842.

8. Orogade AA, Falade CO, Okafor HU, Mokuolu OA, Mamman Al, Ogbonu TA, Ogunkunle OO, Ernest KS, Callahan MV, Hamer DH: Clinical and laboratory features of congenital malaria in Nigeria. Pediatr Infect Dis J 2008, 3:181-187.

9. Vanga-Bosson HA, Coffie PA, Kanhon S, Sloan C, Kouakou F, Eholie SP, Kone M, Dabis F, Menan H, Ekouevi DK: Coverage of intermittent prevention treatment with sulphadoxine-pyrimethamine among pregnant women and congenital malaria in Côte d'Ivoire. Malar J 2011, 10:105.

10. Gitau GM, Eldred JM: Malaria in pregnancy: clinical, therapeutic and prophylactic considerations. Obstet Gynecol 2005, 7:5-11.

11. WHO: Severe falciparum malaria. Trans R Soc Trop Med Hyg 2000 94(Suppl 1):1-90.

12. Snow RW, Nahelen B, Palmer A, DonNelly CA, Gupta S, Marsh K: Risk of severe malaria among African infants: direct evidence of clinical protection during early infancy. J Infect Dis 1998, 3:819-822.

13. Wagner G, Koram K, Mcguinness D, Bennett S, Nkrumah F, Riley E: High incidence of asymptomatic malaria infections in a birth cohort of children less than one year of age in Ghana, detected by multicopy gene polymerase chain reaction. Am J Trop Med Hyg 1998, 59:115-123.

14. Opare DA: Congenital malaria in newborn twins. Ghana Med J 2010, 44:76-78.

15. Zenz W, Trop M, Kollaritsch H, Reinthaler F: Congenital malaria due to Plasmodium falciparum and Plasmodium malariae. Wien Klin Wochenschr 2000, 112:459-461.

16. Opiyo $\mathrm{N}$, English $\mathrm{M}$ : What clinical signs best identify severe illness in young infants aged $0-59$ days in developing countries? a systematic review. Arch Dis Child 2011, 96:1052-1059.

17. Mazzi E, Bartos AE, Carlin J, Weber MW, Darmstadt GL: Bolivia Clinical Signs Study Group: Clinical signs predicting severe illness in young infants (<60 days) in Bolivia. J Trop Pediatr 2010, 56:307-316.

18. World Health Organization: Implementation of the Global Malaria Strategy, WHO Geneva Technical record Series no. 83. Geneva: WHO; 1993.

19. Iqbal J, Hira PR, Sher A, Al-Enezi AA: Diagnosis of imported malaria by Plasmodium Lactate Dehydrogenase (pLDH) and histidine-rich protein 2 (HRP2)-based immunocapture assays. Am J Trop Med Hyg 2001, 64:20-23.

20. Bereczky S, Mårtensson A, Pedro Gil J, Farnert A: Rapid DNA extraction from archive blood spots on filter paper for genotyping of Plasmodium falciparum. Am J Trop Med Hyg 2005, 72:249-251.

21. Kassberger F, Birkenmaier A, Khattab A, Kremsner PG, Klinkert MQ: PCR typing of Plasmodium falciparum in matched peripheral, placental, and umbilical cord blood. J Parasitol Res 2002, 88:1073-1079.

22. Brabin BJ: Congenital Malaria - a recurrent problem. Ann Trop Paediatr 2007, 27:95-98.

23. Mukhtar MY, Lesi FE, Iroha EU, Egri-Okwaji MT, Mafe AG: Congenital malaria among inborn babies at a tertiary centre in Lagos. Nigeria J Trop Pediatr 2006, 52:19-23.
24. Uneke CJ: Congenital malaria: an overview. Tanzan J Health Res 2011, 13:264-280.

25. Reyburn H, Mbatia R, Drakeley C, Carneiro I, Mwakasungula E, Mwerinde O, Saganda K, Shao J, Kitua A, Olomi R, Greenwood BM, Whitty CJ: Overdiagnosis of malaria in patients with severe febrile illness in Tanzania: a prospective study. BMJ 2004, 329:1212.

26. Oduwole OA, Oduwole OA, Ejezie GC, Odey FA, Oringanje CM, Nwakanma D, Bello S, Oriero E, Okebe J, Alaribe AA, Etuk S, Meremikwu M: Congenital malaria in Calabar, Nigeria: the molecular perspective. Am J Trop Med Hyg 2011, 84:386-389.

27. Coll O, Menendez F, Botet, Dayal R, World Association of Perinatal Medicine Perinatal Infections Working Group: Treatment and prevention of malaria in pregnancy and newborn. J Perinat Med 2008, 36:15-29.

28. Mwangoka GW, Kimera SI, Mboera LEG: Congenital Plasmodium falciparum infection in neonates in Muheza district. Tanzania Malar 2008, 7:117.

29. Koita OA, Doumbo OK, Ouattara A, Tall LK, Konaré A, Diakité M, Diallo M, Sagara I, Masinde GL, Doumbo SN, Dolo A, Tounkara A, Traoré I, Krogstad DJ: False-negative rapid diagnostic tests for malaria and deletion of the histidine-rich repeat region of the hrp2 Gene. Am J Trop Med Hyg 2012, 86:194-198.

30. Mwaniki MK, Talbert AW, Mturi FN, Berkley JA, Kager P, Marsh K, Newton CR: Congenital and neonatal malaria in a rural Kenyan district hospital. an eight-year analysis. Malar J 2010, 9:313.

31. Okiro EA, Alegana VA, Noor AM, Mutheu JJ, Juma E, Snow RW: Malaria paediatric hospitalization between 1999 and 2008 across Kenya. BMC Med 2009, 7:75

32. Sievers AC, Lewey J, Musafiri P, Franke MF, Bucyibaruta BJ, Stulac SN, Rich ML, Karema C, Daily JP: Reduced paediatric hospitalizations for malaria and febrile illness patterns following implementation of communitybased malaria control programme in rural Rwanda. Malar J 2008, 7:167.

doi:10.1186/1475-2875-12-17

Cite this article as: Enweronu-Laryea et al:: Prevalence of congenital malaria in high-risk Ghanaian newborns: a cross-sectional study. Malaria Journal 2013 12:17.

\section{Submit your next manuscript to BioMed Central and take full advantage of:}

- Convenient online submission

- Thorough peer review

- No space constraints or color figure charges

- Immediate publication on acceptance

- Inclusion in PubMed, CAS, Scopus and Google Scholar

- Research which is freely available for redistribution 